\title{
REPRESENTAÇÃO, DELIBERAÇÃO E ESTUDOS LEGISLATIVOS
}

\section{Marta Mendes da Rocha}

\section{Introdução}

O presente artigo aborda a relação entre representação e deliberação, problematizando a forma como esses temas vêm sendo tratados no campo dos estudos legislativos. Apesar de o tema da deliberação vir recebendo grande atenção na teoria democrática contemporânea, ele tem sido negligenciado pelos estudiosos do Poder Legislativo. Da mesma forma, os estudiosos da democracia deliberativa apenas secundariamente focam a dimensão da deliberação no contexto das instituições representativas clássicas, como os parlamentos. Esse fato deixa uma lacuna na teoria democrática contemporânea quando se considera que a deliberação é um elemento crucial da democracia e uma dimensão componente do processo legislativo ao lado de outras formas

Artigo recebido em agosto/2009

Aprovado em abril/2010 de interação política e de métodos de tomada de decisão. Além disso, parece consagrar a ideia de que os parlamentos, da forma como se estruturam nas democracias contemporâneas, não são uma arena propícia à deliberação.

A deliberação é entendida aqui como processo de argumentação e troca de informações por meio do qual os participantes podem convencer e persuadir os outros sobre a desejabilidade e a viabilidade de uma proposta. Embora os parlamentos tenham passado por expressivas modificações em seu formato, organização e procedimentos, várias das regras atualmente em vigor, na maioria das casas legislativas, existem porque se concebe esse corpo como um órgão colegiado e deliberativo, no sentido aqui proposto.

Neste artigo sustenta-se o argumento de que o modelo informacional de organização legislativa apresenta importantes nexos com o tema da deliberação. Não se trata de um insight original, uma vez 
que outros autores já haviam apontado a existência de pontos de encontro entre ambas as dimensões (Krehbiel, 1991; Limongi, 1994). Entretanto, até o momento, na ciência política, são poucos os estudos que buscaram abordar essas convergências de maneira sistemática. O objetivo deste trabalho é avançar no desenvolvimento desse argumento mostrando que o modelo informacional pode se converter em uma alternativa viável para apreender a dinâmica deliberativa da política parlamentar, possibilitando compreender como o debate toma parte do processo decisório no âmbito do parlamento e quais são as condiçôes que favorecem uma deliberação informada.

$\mathrm{Na}$ primeira seção discute-se a distinção entre deliberação, negociação e agregação. Na segunda, é mostrado como, nos primórdios do governo representativo, deliberação e representação eram elementos indissociáveis, e uma especificidade do parlamento era justamente seu caráter deliberativo. Na terceira seção, analisam-se as teorias positivas de organização legislativa e as razões pelas quais elas relegaram a um segundo plano o tema da deliberação. Na quarta seção, discutem-se as relações entre deliberação, representação e estratégia, buscando mostrar a possibilidade de compatibilizar esses elementos em uma abordagem sobre a deliberação parlamentar. $\mathrm{Na}$ quinta, mostra-se que o modelo informacional de organização legislativa apresenta importantes nexos com o tema da deliberação sendo, por isso, uma referência teórica e analítica para a sua investigação no âmbito do parlamento. $\mathrm{Na}$ sexta seção, são apresentadas sugestóes para o esboço de um modelo analítico focado na investigação da dimensão deliberativa dos processos decisórios nas casas legislativas. Por último, são apresentadas as considerações finais.

\section{Deliberação, negociação e agregação}

No presente artigo a deliberação ${ }^{1}$ é entendida, no contexto do parlamento, como um processo de argumentação em torno de políticas e resultados, pelo qual os legisladores podem formar e transformar as preferências uns dos outros e do público em geral. Tal ideia não pressupóe que os legisladores estejam comprometidos com a busca do interesse público ou que a deliberação sempre resultará em consenso ou transformação de preferências. A ênfase está no processo deliberativo e não em seus resultados. ${ }^{2}$

Como afirma Elster (1998), nas sociedades democráticas, a maioria dos processos de tomada de decisões políticas combina três métodos distintos: argumentação, barganha e voto. Um dos maiores obstáculos para se abordar o tema da deliberação no contexto do parlamento e que, certamente, tem desencorajado abordagens a respeito, consiste nas dificuldades para se distinguir a negociação e a barganha da deliberação propriamente dita. No nível conceitual, essa distinção é mais clara.

A deliberação distingue-se da negociação e da barganha pelo fato de que estas últimas, em geral, não têm como objetivo o convencimento, a formação e a transformação de preferências. A negociação, na maioria das vezes, resume-se a acordos por meio dos quais nenhuma das partes se dispóe a alterar seus pontos de vista ou objetiva alterar a opinião de outros. O acordo, neste caso, resulta menos do convencimento e mais de concessóes feitas em relação a determinadas matérias e durante um limitado período de tempo, influenciado pelo poder de barganha de cada uma das partes. $\mathrm{O}$ fator intertemporal é importante porque negociações só se tornam críveis se tomadas em um contexto no qual as concessões feitas hoje possam ser retribuídas amanhã (Sartori, 1994).

Diferentemente da negociação, a persuasão e o convencimento distinguem-se pelo emprego da fala e do uso de argumentos racionais e razoáveis. Racionais, porque a deliberação, geralmente, se caracteriza pela discussão em torno da relação entre meios e fins (Przeworski, 1998). Razoáveis, porque em um contexto de democracia e pluralismo político, os indivíduos, ainda que não sejam indiferentes aos seus valores e interesses, são constrangidos pela necessidade de coordenar seu interesse particular com outros interesses e valores e com o benefício de um número maior de pessoas. ${ }^{3}$

A deliberação também se distingue da agregação de preferências porque, se na primeira, o que conta são as razões apresentadas em sustentação às propostas, na segunda, o que vale é o número dos que as apoiam ou as rejeitam. Na prática, porém, não 
é tão simples distinguir essas três formas de interação, principalmente a negociação da deliberação. A possibilidade de tal distinção e os ganhos analíticos dela decorrentes são questóes a serem exploradas. Acredita-se que negociação e deliberação apresentam atributos bastante específicos e, em alguma medida, observáveis e passíveis de serem captados por esquemas analíticos e classificatórios adequados.

\section{Deliberação e representação}

Nas concepções originais sobre a democracia representativa e o parlamento, deliberação e representação eram dimensões estreitamente associadas. O governo representativo não era compreendido unicamente como uma maneira de operacionalizar a democracia nas sociedades complexas, mas como uma forma superior de governo popular. Para os contemporâneos do advento do governo representativo, a representação funcionaria como um filtro através do qual seria possível refinar e ampliar as perspectivas do público, permitindo aos legisladores o distanciamento necessário para fugir das tentações imediatistas e do particularismo (Hamilton et al., 1984).

Aqueles que pensavam a democracia representativa nos séculos XVIII e XIX ${ }^{4}$ acreditavam que os representantes eleitos não eram simples transmissores das vontades dos cidadãos e que, uma vez no parlamento, eles não deveriam afirmar vontades já formuladas por seus eleitores, mas deliberar e votar livremente de acordo com o seu próprio julgamento. A assembleia, como um órgão colegiado, era vista como a melhor oportunidade para a deliberação (Manin, 1995).

Manin argumenta que uma evidência da associação original entre o parlamento e o debate é o fato de a ideia do mandato imperativo nunca ter sido colocada em prática. Além disso, segundo o autor, a associação do governo representativo à ideia de governo do debate foi algo que se deu mais na prática do que na teoria. Para os fundadores do governo representativo, para os quais não fazia sentido que a representação fosse realizada por um único indivíduo, o surgimento da assembleia era natural e, por conseguinte, do debate. $\mathrm{O}$ elo que levava da assembleia representativa ao governo deliberativo era o princípio da igualdade política que, nos séculos XVIII e XIX, começava a se impor sobre a origem, a riqueza e o status.

Os fundadores do governo representativo não devem, no entanto, serem interpretados de forma idealizada, pois, em sua maioria, defendiam o sufrágio restrito e tinham uma visão elitista da política. Em geral, os pensadores da época acreditavam que o processamento dos conflitos sociais deveria ficar a cargo de homens patrióticos, cuja educação e origem nobre os tornavam aptos a julgar com maior distanciamento e moderação. ${ }^{5}$ De fato, a ênfase sobre a dimensão deliberativa esteve mais tradicionalmente associada ao pensamento conservador do que à tradição democrática.

Acredita-se, no entanto, ser possível e desejável recuperar alguns elementos do pensamento daqueles autores - sobretudo a estreita relação entre representação e deliberação - em um marco de pluralismo e igualdade política. No contexto das democracias contemporâneas, a importância da deliberação repousa, não sobre os atributos pessoais daqueles que deliberam, mas sobre o contexto do órgão colegiado que oferece aos representantes melhores condições do que as que são oferecidas aos cidadãos, para identificar seu "melhor interesse" e os meios mais adequados para a sua consecução. ${ }^{6}$

\section{Deliberação e estudos legislativos}

A ideia, cara aos teóricos do governo representativo, de que seria possível, no contexto do parlamento, buscar soluções para os problemas da coletividade mediante o debate racional não sobreviveu ao século XX e às transformações ocorridas na política democrática. Com a expansão do sufrágio e o surgimento dos partidos políticos de massa, alguns autores passaram a questionar o caráter deliberativo do parlamento (Manin, 1995). Para Weber (1982), no início do século XX, a política tomava a forma de uma luta partidária por votos e cargos, na qual o debate em torno de ideias e programas havia ficado para segundo plano. Schumpeter (1961), por sua vez, empreendeu uma dura crítica à ideia de que os cidadãos ou seus representantes fossem capazes 
de, por meio do debate racional, encontrar soluçōes para os problemas coletivos ou chegar a decisōes que pudessem ser consideradas racionais.

Essa visão influenciou perspectivas posteriores a respeito da democracia e do processo legislativo, nas quais a preocupação com a dimensão deliberativa da política parlamentar esteve ausente. Tal preocupação só foi retomada recentemente a partir dos trabalhos de Jürgen Habermas. Por influência de seus escritos, o tema da deliberação passou a ser exaustivamente tratado no seio do que se convencionou chamar de teoria deliberativa da democracia (Gutmann e Thompson, 1996; Habermas, 1997; Cohen, 1997; Bohman, 1997; Young, 1997; Avritzer, 2000).7 Entretanto, a revalorização do elemento argumentativo não motivou, por parte desses mesmos estudiosos, o interesse em investigar a deliberação no contexto das instituições representativas formais, sobretudo nos parlamentos. Embora os autores reconheçam a indispensabilidade da representação nas sociedades contemporâneas para se operacionalizar a democracia, na prática, a maioria dos estudos sobre deliberação democrática foca sua atenção e tem como objetos primordiais as instituiçôes participativas, formais ou informais, situadas fora do sistema político, na esfera pública.

Esse fato, provavelmente, está relacionado com o diagnóstico habermasiano de que o sistema político seria uma esfera "colonizada", caracterizada por relações verticais e hierarquizadas, o que levaria os teóricos deliberativos a crer que o parlamento não seria uma arena propícia à deliberação (Habermas, 1997; Avritzer, 1996). Restaria, então, às arenas de participação ampliada da esfera pública o papel de produzir, via deliberação, um poder gerado comunicativamente, fonte de legitimidade das decisōes tomadas pelos agentes públicos (Habermas, 1997). Assim, privilegia-se o tema da deliberação, mas negligencia-se a arena parlamentar.

As teorias positivas de organização legislativa ${ }^{8}$ que são, hoje, as referências principais nos estudos legislativos, ao contrário, privilegiam a arena parlamentar como objeto de estudo, mas negligenciam a dimensão deliberativa. Os três modelos de organização legislativa - distributivista, informacional e partidário - apesar de suas diferenças, compartilham a premissa de que os legisladores buscam atingir seus objetivos - primordialmente a sua reeleição - ao menor custo possível (Shepsle e Weingast, 1987; Weingast e Marshall, 1988; Gilligan e Krehbiel, 1987; Krehbiel, 1991; Cox e McCubins, 1993). No contexto norte-americano, onde há uma forte identificação entre o representante e seus eleitores, geograficamente concentrados em distritos uninominais, perseguir a reeleição quase sempre significa perseguir benefícios concentrados para suas respectivas bases eleitorais (Shepsle e Weingast, 1987; Weingast e Marshall, 1988). Nas três abordagens, considera-se que, deixados à própria sorte, os parlamentares empenhar-se-ão na busca de ganhos distributivos que os beneficiem individualmente. Entretanto, considerando-se o papel das instituiçôes na produção de incentivos e na formatação das estratégias individuais, afirma-se que será a organização legislativa que definirá a forma como os legisladores perseguirão aquele objetivo.?

$\mathrm{Na}$ abordagem distributivista, as preferências são vistas como formatadas exogenamente ao processo político e os parlamentares, como seus simples vetores (Mayhew, 1974). Não se leva a sério a possibilidade de que, no contexto de um órgáo colegiado, os parlamentares possam transformar suas preferências, por meio da deliberação, e chegar a novas conclusōes sobre quais seriam os melhores interesses dos cidadãos. Nessa vertente, atribui-se papel central às comissôes. Entretanto, essa importância não decorre do fato de que, sendo colegiados menores, nos quais é possível a interação face a face, as comissões seriam mais propensas à deliberação. Diferentemente, as comissões são vistas como espaços de aquisição de ganhos de troca pelos parlamentares (Shepsle e Weingast, 1987; Weingast e Marshall, 1988). Funcionando como espécies de comitês (Sartori, 1994), as comissōes possibilitariam aos legisladores realizarem acordos intertemporais, nos quais todos teriam a expectativa de ganhos em algum momento.

Para o modelo partidário, as comissóes também são instâncias centrais, mas apenas como meios pelos quais os partidos políticos, sobretudo o majoritário, podem exercer controle sobre a agenda e o ritmo da produção legislativa de modo a aprovar políticas coerentes com suas preferências (Cox e McCubbins, 1993). 
Obviamente, as teorias positivas de organização legislativa são bem mais complexas do que pode parecer aqui. $\mathrm{O}$ que interessa notar é que, tanto para a visão distributivista como para a partidária, a deliberação parece não desempenhar qualquer papel no processo legislativo. Os métodos de tomada de decisão aqui considerados são a barganha (entre parlamentares individuais e lideranças e entre os líderes e os liderados) e o voto.

Embora as teorias positivas de organização legislativa não se baseiem em uma reflexão profunda sobre a natureza da representação democrática, pode-se afirmar que elas compartilham a premissa de que a forma como os parlamentos contemporâneos encontram-se organizados reserva muito pouco espaço para a deliberação. Este ponto é desenvolvido por Gardner (2005) em uma reflexão sobre a relação entre deliberação e representação, tendo como parâmetro o Congresso norte-americano. O autor afirma que, embora os idealizadores das instituições representativas norte-americanas atribuíssem grande importância à deliberação, ter-se-ia consolidado, ao longo do tempo, uma forma de organização legislativa baseada em uma concepção pluralista da representação de interesses que consagra a visão dos representantes como delegados de interesses específicos. Dessa forma, segundo o autor, para servir aos seus propósitos democráticos e representativos, ter-se-ia comprometido a dimensão deliberativa do Congresso.

As características organizacionais centrais do Congresso norte-americano - compartilhada por outras casas legislativas ao redor do mundo - violariam, segundo o autor, algumas das condições propaladas pela literatura como fundamentais à deliberação, entre elas a autonomia dos legisladores e a igualdade entre os participantes do processo (Cohen, 1997; Gardner, 2005). No contexto do parlamento, os legisladores estariam constrangidos pelos vínculos com sua constituency, cabendo a eles desempenharem o papel de delegados e advogados de interesses locais, não havendo, portanto, incentivo ou abertura para a persuasão mútua. $\mathrm{O}$ problema consistiria em agregar vontades previamente definidas.

Além disso, as regras e os procedimentos de organização legislativa violariam o princípio da igualdade, que também seria crucial em uma arena deliberativa. A necessidade de dividir e coordenar o trabalho em uma casa legislativa de grandes proporçôes teria gerado uma forte hierarquia pautada em uma divisão desigual de recursos e prerrogativas entre líderes e liderados, plenário e comissões (Gardner, 2005). Os representantes seriam iguais somente no tocante ao voto, mas desiguais em relação a uma série de outros recursos, entre eles, a informação, tão crucial em um processo deliberativo.

Como já afirmado, embora algumas das transformaçôes ocorridas no formato da democracia representativa tenham contribuído para a restrição dos espaços de discussão no interior do parlamento, não se pode afirmar categoricamente que o debate não desempenhe papel importante na política parlamentar ou que o Legislativo não seja uma arena propícia à deliberação. A narrativa política cotidiana evidencia com bastante clareza que o debate é parte do processo político (Elster, 1998; Gambetta, 1998). Ao propor um projeto de lei, governos, partidos e legisladores individuais também apresentam as razões que justificam sua necessidade, importância e viabilidade. Não raro, esses atores vêm a público justificar suas posiçôes perante a sociedade, quando, então, o debate extrapola os muros do parlamento, alcança a grande mídia e, em alguns casos, os grupos de interesse e os cidadãos comuns.

As teorias que pressupunham que as preferências individuais fossem dadas e, portanto, que o processo político consistiria em sua simples agregação, como é o caso dos modelos econômicos de democracia (Downs, 1999), há muito foram questionadas e de forma bastante eloquente. Essa premissa, herdada da economia, mostrou-se insustentável na ciência política (Jones, 1994). Mayhew (2006), em trabalho recente, reformulou seu ponto de vista original reconhecendo que o exercício da representação no parlamento possui feições bem mais complexas, não podendo ser reduzido à simples perseguição de vontades formuladas fora da arena política. Este ponto também é sustentado por March (1986), Przeworski (1995), Elster (1994, 1997) e Jones (1994), que compartilham da visão de que "é razoável que os indivíduos mudem suas preferências como resultado de sua mútua comunicação" (Przeworski, 1995, p. 25) e de que "pre- 
ferências políticas não podem ser tomadas como fixas, porque muito do processo político consiste na persuasão sobre cursos de ação preferidos" (Jones, 1994, p. 33, tradução nossa). ${ }^{10}$ Observa-se um intenso interesse em compreender como se formam as preferências e os valores dos cidadãos no campo dos estudos sobre comportamento eleitoral e sobre como suas preferências são afetadas pela exposição a novas informações e experiências (Jones, 1994). No campo dos estudos legislativos, entretanto, pouca atenção tem sido dada à forma como as preferências políticas dos legisladores se formam e se transformam ao longo do processo político. Assim, o tema da deliberação parlamentar, que diz respeito justamente a como isso ocorre, tem sido relegado a um segundo plano, o que leva a pensar que exista uma disjunção entre as ideias de deliberação e representação ou entre deliberação, negociação e agregação.

Pode-se apontar pelo menos duas razôes que auxiliam a explicar a persistência dessa lacuna. Em primeiro lugar, pode-se argumentar que alguns pressupostos da escolha racional - atores racionais movidos exclusiva ou primordialmente pelo autointeresse e por preferências dadas e fixas - parecem não se coadunar com a noção de deliberação, na qual os participantes se abrem para a persuasão mútua. Nesse entendimento, a premissa do comportamento maximizador e o forte componente estratégico da escolha racional estariam em conflito com a ideia de um procedimento deliberativo por meio do qual os atores formam e transformam suas preferências com base na troca de argumentos razoáveis. Criar-se-ia aqui uma oposição entre uma perspectiva realista que pretende abordar os problemas políticos da forma como eles se manifestam e uma abordagem mais normativa comprometida, ao mesmo tempo, com a crítica dos processos políticos nos moldes em que ocorrem nas democracias contemporâneas e com a elaboração de prescrições sobre como esses processos deveriam ocorrer.

De fato, grande parte dos adeptos da escolha racional mostra-se bastante cética em relação à possibilidade de que a deliberação venha a se tornar uma dimensão importante no processo político. Vários autores consideram que, mesmo na presença de incentivos adequados, é pouco provável que os indivíduos se disponham a resolver suas diferenças por meio de um processo deliberativo ou que este realmente tenha impactos significativos sobre os resultados políticos (Przeworski, 1998; McCubbins e Rodriguez, 2006).

Em segundo lugar, pode-se dizer que o instrumental metodológico característico da escolha racional limita sua capacidade de lidar com o aspecto dinâmico da política parlamentar, incluindo aí a dimensão deliberativa. Os estudos informados por essa abordagem assumem como premissas que os indivíduos possuem preferências delimitadas, são capazes de hierarquizar essas preferências e agem, estrategicamente, no sentido de alcançar seus objetivos. Tal perspectiva se caracteriza por uma deliberada simplificação da realidade social, de modo que se possa abordar, na forma de dilemas e de métodos com alto nível de formalização (técnicas de modelagem, por exemplo), uma série de situações nas quais esteja presente algum problema de ação coletiva (Morrow, 1994). Se, de um lado, esses pressupostos e técnicas permitem ganhos em capacidade de generalização e maior rigor lógico, de outro, impõem uma série de restrições à realidade que limita a capacidade dessa abordagem para a compreensão do processo legislativo em toda a sua dinâmica, sobretudo no que se refere à formação e à transformação endógena de preferências, que não resulte simples e unicamente de negociação, de cálculo ou de adaptação (Tsebelis, 1998).

Tais colocações poderiam levar à conclusão de que a abordagem da escolha racional e as perspectivas analíticas dela derivadas não seriam referências profícuas para o estudo da deliberação. Neste artigo, no entanto, sustenta-se posição diferente. Esse argumento será desenvolvido nas próximas seções quando se buscará mostrar que a teoria informacional de organização legislativa pode ser um interessante ponto de partida para o estudo da deliberação parlamentar.

\section{Deliberação, representação, interesses e estratégia}

Neste artigo não se compartilha de alguns pressupostos defendidos pelos "teóricos deliberativos" (Habermas, 1997; Bohman, 1997; Cohen, 1997; 
Gutmann e Thompson, 1996; Avritzer, 2000), entre eles, o de que a deliberação seria a única forma de justificação política nas sociedades democráticas ou de que os resultados de decisões tomadas mediante deliberação seriam sempre superiores, mais racionais ou mais legítimos do que os resultados originados de outras formas de decisão. ${ }^{11}$ Não se ignora que o processo deliberativo possa ser dificultado por obstáculos tais como a pressão do tempo e a necessidade de tomar decisōes de forma rápi$\mathrm{da}$, a desigualdade entre os atores que participam do processo, o uso da hipocrisia por parte daqueles que, reconhecendo não ser suficiente sustentar uma proposta com base em razóes pessoais ou estreitas, buscam travestir de interesse geral seus interesses particulares (Przeworski, 1988; Elster, 1997). Deve-se considerar, ainda, que a deliberação, da mesma forma que pode favorecer a construção de consensos e acordos, também pode levar a uma exacerbação do conflito e ao agravamento do dissenso (Johnson, 1998).

Também vale enfatizar que a noção de interesses, quando aqui utilizada, não possui conotação negativa. Não se parte da ideia de que os interesses sempre representam pontos de vista estreitos ou uma motivação egoística. Toma-se o termo interesse em sua acepção mais simples que denota as preferências, os desejos e os objetivos de um ator. Assim como a perspectiva da escolha racional, reconhece-se que os benefícios políticos são limitados e os atores possuem preferências diversas, às vezes, irreconciliáveis. Nesse sentido, a dimensão competitiva sempre será um aspecto relevante do processo político.

Acredita-se haver várias razões que tornam a deliberação um elemento importante do processo legislativo a ser investigado e compreendido. Em primeiro lugar, reconhece-se que a democracia, em seus diversos moldes, quase sempre esteve associada à ideia do debate. A própria democracia representativa, como já afirmado, nasceu embebida nessa ideia que, por sua vez, sustenta-se no princípio da igualdade política.

Outra razão consiste em considerar que a deliberação, ao permitir que cidadãos e representantes troquem ideias e informaçôes, que interesses e pontos de vista sejam confrontados, funciona como uma ferramenta que pode aperfeiçoar a representação (Elster, 1998, p. 13). ${ }^{12}$ Primeiro e mais simples, levando os representantes a tomarem decisōes mais informadas e mais conducentes aos fins desejados. Não é trivial, em se tratando de um regime democrático, saber como o parlamento delibera sobre políticas, quão bem informados são os parlamentares quando tomam decisões políticas e quais são as condições que favorecem a deliberação informada (Mucciaroni e Quirk, 2006).

Acredita-se que aparentes disjunções entre representação e deliberação observadas em determinadas abordagens sobre o processo político ocorrem, na realidade, por estas abordagens tomarem como ponto de partida uma visão estreita sobre o que seja o ato de representar.

Tome-se, por exemplo, o livro The voice of people de James Fishkin (1995), no qual o autor vale-se do enredo de um filme chamado Magic town para abordar o tema da deliberação política. No filme, descobre-se que uma cidade fictícia do meio-oeste norte-americano constituía uma amostra representativa da população do país, passando a ser usada por um instituto de pesquisas para a realização de surveys a custos menores. Ao tomarem conhecimento desse fato, os moradores da cidade passam a se preocupar cada vez mais com as opiniōes que emitirão e começam a se informar mais detidamente sobre os temas sobre os quais são convidados a opinar. Dedicando-se a um processo de deliberação, os moradores começam a formar novas opiniōes $\mathrm{e}$, aos poucos, como se poderia esperar, suas opiniōes deixam de espelhar o que pensa o cidadão norteamericano comum. Como assinalam Anastasia e Inácio, "o debate e a deliberação pública acarretaram alteraçōes nas definições dos cidadãos relativamente a quais eram e onde estavam os seus melhores interesses" (2006, mimeo.).

Tomando a cidade como uma metáfora do parlamento, se é levado a pensar que à medida que os representantes começaram a deliberar e a se informar sobre diversos temas, sua opinião começou a se afastar das preferências e das opiniōes dos cidadãos que eles representavam. Partindo-se de uma visão do parlamentar como vetor de vontades formuladas exogenamente à arena política, como o faz a teoria distributivista, poder-se-ia concluir que a de- 
liberação acarretou um problema para a representação. Por outro lado, considerando-se que o ato de representar consiste também e, talvez, sobretudo, em formular vontades a partir das preferências manifestas pelos eleitores, poder-se-ia concluir justamente o contrário: que a deliberação aperfeiçoou a representação! Portanto, a forma como se compreende a representação tem implicações diretas para se pensar suas relações com a deliberação. Ao se considerar, como o fazem, por exemplo, Pitkin (1967) e Manin (1995), que a representação não se materializa nas características dos representantes ou em sua identificação descritiva com os representados, mas, no comportamento dos legisladores e no contexto em que a representação se realiza, têm-se uma noção de representação perfeitamente compatível com a ideia de deliberação (Gardner, 2005).

Mas, por que os parlamentares, em vez de simplesmente se dedicarem a um jogo de construção de acordos por meio de trocas intertemporais de apoio, se empenhariam a resolver o desacordo mediante a discussão? Tem sido comum em várias democracias contemporâneas encarar as deliberações ocorridas no parlamento mais como um jogo de cena, um "jogar para a plateia” sem sentido prático, uma vez que as decisões já estariam predeterminadas por acordos feitos entre os partidos ou por compromissos assumidos com o governo. Embora esta seja uma possibilidade concreta, ela não diz tudo sobre a política parlamentar. Afinal, a consolidação dos procedimentos democráticos é um processo que, em seu desenrolar, torna a justificação das decisões políticas um ingrediente fundamental. Nesse processo, os representantes mobilizam a sociedade e buscam moldar opiniōes sobre quais seriam os melhores resultados e as melhores políticas. E claro, não se trata de um processo de mão única. Os atores políticos também são influenciados pelos valores, identidades, opiniōes e pelas preferências dos diferentes grupos da sociedade.

Além disso, como argumentam Mucciaroni e Quirk (2006), os parlamentares podem usar o debate como estratégia para persuadir seus pares dos méritos substantivos de uma proposta ou posição política, para mobilizar apoio e reduzir a oposição dos eleitores em torno de uma decisão, para reivindicar crédito político por suas posiçōes e para forta- lecer sua credibilidade e sua reputação como especialistas. Esses diferentes usos, é claro, diferenciam os processos deliberativos e, nesse artigo, o foco recai sobre o primeiro tipo. Afinal, a persuasão é a estratégia que apresenta menores custos se o parlamentar possui informação ou tem fácil acesso a ela. É razoável supor que os parlamentares lancem mão desse recurso quando observam a possibilidade de sucesso. A tendência em considerar que os parlamentares se restringem ou priorizam a negociação e a barganha é um resultado da premissa questionável de que suas preferências são dadas e fixas e de que os parlamentares, em sua grande maioria, não se mostram dispostos a serem persuadidos.

Deve-se considerar também que, se há uma associação entre a troca de informações e o processo deliberativo, é coerente afirmar que a preocupação com a crescente complexidade envolvendo a elaboração e a implementação de políticas públicas pode levar os legisladores a atribuírem maior valor à troca de informações no processo decisório.

Esse ponto é defendido por Reis para quem é possível distinguir a ação racional pelo grau de abertura do ator. Segundo ele, a ação racional de um sujeito autônomo, cujas ações se compóem de intencionalidades e visam à eficácia, não se confunde com a busca cega de fins definidos previamente a partir de um foco de identidade. $\mathrm{O}$ autor argumenta que a fidelidade a certos objetivos, se é um componente da ação racional, deve ser equilibrada por outros requisitos, tais como a abertura, a disposição de comunicar e intercambiar e de "permitir que a informação presumida seja intersubjetivamente controlada como condição de sua "objetividade" (2000, p. 65). Assim torna-se possível falar em "graus de racionalidade" dependentes do "volume de informaçōes processadas" (Idem, ibidem). Os constrangimentos impostos à ação dos representantes políticos, seja pelos incentivos gerados pelo método eleitoral, seja pelo pertencimento a um partido político, assemelham-se aos constrangimentos impostos a todo e qualquer indivíduo na esfera societária. Se eles distribuem incentivos, limitam estratégias, cursos de ação e moldam preferências, eles não as determinam, caso em que o atributo da incerteza inerente à democracia se encontraria ameaçado. 
Uma questão de fundo nesse debate refere-se à forma pela qual a deliberação se combina às ideias de estratégia e de cálculo, se tais dimensões são compatíveis entre si ou, ao contrário, excluem-se mutuamente. Como mostra Riker (1986), a deliberação, entendida como debate envolvendo troca de argumentos, é parte fundamental do processo decisório. Entretanto, ela está estreitamente ligada a um esforço por controlar os procedimentos, a forma e o ritmo por meio dos quais a decisão é tomada e está sujeita à desigualdade de recursos entre os atores políticos. A decisão por deliberar, nesse sentido, pode expressar, muitas vezes, uma escolha estratégica. Portanto, o cálculo e a estratégia não seriam característicos apenas dos processos de negociação, barganha e agregação de preferências, nos quais um ator busca manipular as condições e os procedimentos de decisão a seu favor contando com os recursos de que dispõe, mas, seria, também, um componente da própria deliberação. Nesse caso, um dos recursos fundamentais seria justamente o controle de informaçôes ou o acesso facilitado a elas.

\section{Modelo informacional de organização legislativa}

Seguindo os trilhos da abordagem neo-institucionalista, é razoável considerar que alguns tipos de organização legislativa podem ser mais conducentes do que outros à deliberação. Acredita-se que, dos três modelos de organização legislativa, o que oferece recursos para se pensar a dimensão da deliberação no processo legislativo é o modelo informacional. Como já afirmado, o próprio Krehbiel reconhece a existência de nexos entre o modelo informacional e a dimensão do debate, mas não avança na sua teorização. Segundo o autor, "as teorias informacionais são prudentes ao não assumir que deliberação e discussão ocorram [...]. Elas apenas caracterizam a escolha de maneira tal que o jogo político contenha um componente de bem comum que, por definição, todos os atores políticos valorizam" (1991, p. 73, tradução nossa). Entretanto, uma questão bastante semelhante a que motiva este artigo também é colocada pelo autor, que se pergunta sob que condiçôes se pode esperar que o processo legislativo contenha uma boa dose de deliberação e se é possível encontrar, no mundo real, legislaturas desenhadas de tal modo que aquelas condiçôes sejam satisfeitas (Idem, ibidem)

A incerteza é um dos postulados básicos do modelo informacional (Gilligan e Krehbiel, 1987; Krehbiel 1991); a ideia de que, uma vez eleitos, os legisladores veem-se em um ambiente onde a informação é um recurso escasso e desigualmente distribuído e, para adquiri-la, é necessário empregar tempo e esforço que poderiam ser mobilizados na perseguição de outros fins. Desse modo os legisladores encontramse numa situação de incerteza quanto à relação entre as políticas e seus prováveis resultados.

Segundo essa abordagem, uma vez que os legisladores têm aversão a riscos, a redução da incerteza, sendo um bem coletivo, interessa a todos. Por essa razão, Krehbiel descreve o problema central das legislaturas como a necessidade de incentivar a especialização dos legisladores e o compartilhamento de informação entre eles (isto é, o uso não estratégico da informação) para benefício da legislatura como um todo, sendo esta uma condição para dotar de maior racionalidade as decisōes. Dessa forma, os legisladores poderiam tomar suas decisões com base no maior volume possível de informações, oriundas de fontes diversas, sendo capazes de avaliar os diferentes aspectos de uma proposta.

Como assinala Krehbiel (1991), a principal resposta ao problema da incerteza no âmbito da representação política foi a divisão do trabalho em sessōes ou comissões. Em princípio, concentrados em um único órgão, os trabalhos legislativos mostravam-se lentos e superficiais. $\mathrm{O}$ aumento no volume das atividades legislativas e do grau de incerteza no ambiente político exigiu dos legisladores a criação de um novo formato capaz de dotar de maior funcionalidade, agilidade e qualidade os trabalhos legislativos (Polsby, 1968). ${ }^{13}$

Outro postulado da abordagem informacional é o majoritário: a ideia de que as decisões tomadas em uma democracia, para serem coerentes com seus princípios balizadores - soberania popular e igualdade política -, devem ser tomadas com base nas preferências da maioria dos membros de uma legislatura. Assim, segundo Krehbiel, uma legislatura informacionalmente organizada caracterizar- 
se-ia pela presença de comissões compostas como microcosmos do plenário (proporcionalmente à distribuição dos partidos na casa) por especialistas em suas respectivas jurisdições. O principal critério para a escolha de membros para as comissóes seria a expertise, ou seja, a capacitação prévia resultante de seu background profissional, e não a autosseleção como propõem os distributivistas. As comissões seriam heterogêneas e contariam com a presença de membros de polos opostos do espectro ideológico condição para que operem sobre uma base informacional plural. Somente assim poder-se-ia esperar que o plenário concedesse vantagens legislativas às comissões. Isso porque qualquer consenso alcançado na comissão poderia ser visto como representativo de um consenso possível no plenário - e como representativo das preferências do legislador mediano.

Assim, diferentemente da abordagem distributivista que enfatiza o papel das comissões como arenas que permitem a obtenção de ganhos de troca, na visão informacional, as comissōes são vistas como espaços que permitem compatibilizar a busca individual por ganhos de troca com o interesse coletivo da legislatura em reduzir a incerteza sobre a relação entre políticas e resultados. O resultado agregado da organização legislativa, segundo o modelo informacional, seria o fortalecimento do Poder Legislativo que se tornaria um órgão com maior capacidade de analisar uma multiplicidade de temas e de produzir decisões e políticas mais bem fundamentadas. Por conseguinte, ter-se-ia um maior equilíbrio entre os poderes. Seria razoável esperar, ainda, a formulação de uma agenda mais diversificada e a aprovação de políticas coerentes, simultaneamente com a realização de objetivos individuais e coletivos (Krehbiel, 1991; Gilligan e Krehbiel, 1987).

Os estudiosos que trabalham em uma perspectiva informacional, em geral, não avançam na teorização dos nexos entre uma organização informacional do parlamento e a dimensão da deliberação. Apesar disso, é possível afirmar que as comissóes parlamentares, como pensadas pelos teóricos informacionais, se constituem em espaços que oferecem interessantes oportunidades para a discussão e o debate. As comissóes criam um contexto decisório no qual são possíveis a interação face a face e a troca de informações e argumentos entre os legisladores. Uma arena onde os representantes podem avaliar os diversos aspectos de uma proposta, levantando seus prós e contras, estimando seus custos e benefícios e seus possíveis efeitos colaterais a partir de uma matriz plural de preferências e informações e do saber especializado de membros e não membros. Resumindo, um espaço no qual os legisladores podem deliberar em vez de simplesmente votar ou barganhar.

Acredita-se que o processo político sob uma organização informacional é perfeitamente compatível com o conceito de deliberação aqui exposto. Trata-se, entretanto, como já afirmado, de um ponto pouco explorado pela literatura.

\section{Notaçóes para o desenvolvimento de um modelo analítico}

A organização informacional do Legislativo pode ser um interessante ponto de partida para incrementar a deliberação na política parlamentar. Nesta seção são apresentados alguns apontamentos que podem contribuir para pensar um modelo analítico que aborde, comparativamente, a relação entre organização informacional e deliberação, em casas legislativas.

Recentemente alguns estudiosos do Legislativo passaram a destacar a importância da deliberação e de sua interface com a informação no processo legislativo. Alguns autores adotam um conceito mais enxuto de deliberação como "cuidadosa consideração antes de decidir", "processo para chegar a decisões informadas, instrumentalmente racionais e consistentes com os objetivos e/ou valores dos decisores" (Mucciaroni e Quirk, 2006). Ou, ainda, como uma forma de discussão em torno dos meios mais adequados para se atingir fins predefinidos (Przeworski, 1998). Outros autores partem de uma concepção mais ampla, entendendo a deliberação como um processo que envolve avaliação racional dos méritos das políticas públicas, compromisso com a perseguição de alguma noção de bem público, uso de informações para a persuasão mútua, abertura dos legisladores para a persuasão e tomada das decisões finais vinculadas ao processo de julgamento racional (Bessette, 1994). 
Assim, a investigação da deliberação parlamentar tem ocorrido sob perspectivas diferentes; em alguns casos, partindo-se de uma visão dos legisladores como comprometidos com a busca de alguma concepção de bem comum (Idem), em outros, a partir de uma visão dos parlamentares como atores auto-interessados que atribuem importância à deliberação como forma de escolher entre diferentes alternativas de políticas (Lascher, 1996).

É possível, então, encontrar diferentes enfoques. Enquanto alguns buscam desenvolver esquemas analíticos inspirados na teoria do discurso de Habermas para o estudo da deliberação parlamentar (Steenbergen et al., 2003), outros trabalham com uma noção mais simples de deliberação, qual seja, como processo de debate e discussão em torno de políticas (Mucciaroni e Quirk, 2006). Há também estudos baseados na realização de experimentos deliberativos que buscam reproduzir o contexto legislativo de modo a investigar em que medida a deliberação produz resultados mais positivos em termos de bem-estar (McCubbins e Rodriguez, 2006) ou sob que condições processos decisórios baseados em negociação podem se converter em processos deliberativos (McLaverty e Halpin, 2008).

Lascher (1996) chama a atenção para os enormes desafios metodológicos em torno do estudo da deliberação parlamentar e para as próprias ambiguidades que o conceito envolve. $\mathrm{O}$ autor busca operacionalizar conceitos na forma de variáveis e indicadores que permitam desenvolver hipóteses testáveis sobre o grau e a qualidade da deliberação nos legislativos. Connor e Oppenheimer (1993) estudaram as mudanças no tempo dedicado à deliberação no plenário do Congresso norte-americano e o número de participantes que falaram e propuseram emendas em processos decisórios levados a cabo entre 1920 e 1980. Steenbergen et al. (2003) analisaram o conteúdo dos debates ocorridos na Câmara dos Comuns britânica para criar um índice de qualidade do discurso derivado da teoria do discurso de Habermas e mensurar em que medida os participantes escutam uns aos outros, justificam suas posições em termos razoáveis, demonstram mútuo respeito e boa vontade para reavaliar suas posiçôes. Landy, Roberts e Thomas (1990) examinaram várias deliberações sobre meio ambiente no
Congresso norte-americano e na Agência de Proteção Ambiental nos anos de 1970.

Algumas das principais questôes discutidas por esses estudiosos são as condiçōes que favorecem e motivam a deliberação parlamentar (Connor e Oppenheimer, 1993; Mucciaroni e Quirk, 2006); os tipos de arranjos institucionais mais conducentes à deliberação (Bachtiger et al., 2005); os efeitos da deliberação sobre o processo decisório e sobre a qualidade das políticas (Mucciaroni e Quirk, 2006), entre outros.

Há também um conjunto de estudos que analisa o aspecto da transmissão da informação nas casas legislativas, em grande parte influenciados pelas teorias informacionais. Em geral, seu foco está em saber como as legislaturas lidam com o problema da incerteza, como proveem, internamente, os legisladores de informações relevantes para a tomada de decisão e como isso influencia a qualidade das políticas. Mas, em geral, os autores não vão além dessas dimensōes, na tentativa de compreender os nexos entre a existência de uma boa estrutura informacional e a qualidade da deliberação parlamentar (Austen-Smith, 1990; Krehbiel, 1991; Sebatier e Whiteman, 1985).

Com o intuito de elaborar um modelo analítico para se estudar a deliberação parlamentar, propõe-se aqui que sejam tomadas como variáveis dependentes o grau e a qualidade da deliberação em um processo decisório. $\mathrm{O}$ primeiro diz respeito a quanto do tempo de tramitação de uma proposição de lei é dedicado ao debate e à discussão, isto é, se o debate em torno das dimensões substantivas das proposiçôes de lei corresponde ou não a uma parte importante do processo. ${ }^{14} \mathrm{O}$ tempo, aqui, é uma dimensão central, seja aquele reservado à discussão pelas regras que regulam a tramitação dos projetos e o uso da fala pelos legisladores, seja o tempo efetivamente utilizado pelos participantes. Em contextos onde haja incentivos para que uma proposição possa ser o mais exaustivamente debatida e estudada e onde o direito da fala seja distribuído de forma mais equitativa entre os participantes, é razoável esperar que seja maior o grau de deliberação.

A quantidade de deliberação é apenas a primeira dimensão a ser observada. Além dela, deve-se verificar a qualidade da deliberação. Segundo Muccia- 
roni e Quirk (2006), a qualidade varia em função das características do contexto, sobretudo as que se referem à informação. Os autores afirmam que a deliberação será tanto mais informada quanto mais os legisladores busquem sustentar seus pontos de vista por meio de uma argumentação baseada em informaçōes técnicas e/ou políticas verificáveis e/ou razoáveis. Ela será tanto menos informada quanto mais os parlamentares façam uso de argumentos de impacto destinados a desqualificar os oponentes ou impressionar a audiência, baseados em visóes superficiais e pouco fundamentadas do assunto. As duas estratégias deliberativas correspondem a dois extremos que podem servir de parâmetro para a análise dos processos decisórios levados a cabo nos parlamentos.

Os autores consideram também que o grau e a qualidade da deliberação resultam da expectativa dos atores em relação à crítica em torno de seus argumentos. Esta, por sua vez, varia em função da disponibilidade de recursos informacionais. Quando se considera que a disponibilidade desses recursos é maior nas casas legislativas organizadas em coerência com o modelo informacional, abre-se um caminho para a construção de um modelo analítico que permita apreender a dimensão da deliberação parlamentar.

A variável independente, portanto, em tal modelo analítico, consiste no grau em que a casa legislativa se organiza segundo o modelo informacional ou, de forma mais concreta, no grau em que a organização legislativa disponibiliza informações de qualidade e oportunidades para a especialização ao conjunto de seus membros. Nesse sentido, um importante indicador é a divisão ou não do trabalho legislativo em comissões parlamentares, o número de comissões, o número de comissões por parlamentar e de parlamentares por comissão. Juntos, esses aspectos indicam o número e os tipos de áreas de políticas sobre as quais os parlamentares teriam oportunidades de deliberar de maneira aprofundada e as oportunidades oferecidas aos legisladores para se especializarem e para participarem ativamente do debate.

Outros indicadores importantes remetem às prerrogativas e aos direitos legislativos assegurados às comissões, que evidenciam sua capacidade de in- fluenciar a agenda e o ritmo do processo legislativo vis-à-vis às lideranças partidárias e o plenário. ${ }^{15}$ $\mathrm{Na}$ teoria informacional, supõe-se que as comissões apenas se empenharão no estudo aprofundado das matérias se nutrirem a expectativa de que suas decisões serão mantidas pelo plenário nas etapas posteriores do processo. Essa expectativa, por sua vez, varia em função do perfil das comissões e das prerrogativas controladas por elas (Krehbiel, 1991).

Outros indicadores relevantes remetem à forma como são compostas as comissões e o seu perfil resultante. Importa saber em que medida as comissões são representativas da casa e compostas por especialistas nas áreas de políticas correspondentes à sua jurisdição. Tais aspectos, além de indicar o número e os tipos de atores admitidos no processo deliberativo, também sinalizam a disponibilidade maior ou menor de recursos informacionais para a casa como um todo.

A existência de um staff institucionalizado central ou descentralizado no âmbito das comissões com membros que possuam qualificação em diferentes áreas e com alta capacidade de responder às demandas dos parlamentares indicaria a maior ou menor capacidade dos deputados para acessar informações a um baixo custo.

A hipótese é a de que na presença de um staff institucionalizado e na presença de comissões representativas, compostas por especialistas, com prerrogativas que lhes permitam exercer algum controle da agenda, cuja estruturação abra espaço para a participação direta dos membros e incentive sua especialização, os parlamentares terão maior facilidade para acessar informações. Dessa forma, seria maior a expectativa dos legisladores em relação à crítica e ao escrutínio de suas propostas, o que os levaria a um processo deliberativo mais informado e rico, marcado pela troca de argumentos embasados em informações e estudos.

Este conjunto de variáveis oferece um ponto de partida para se esboçar as condições que favorecem a deliberação informada no âmbito do parlamento. Sua análise permite pensar em um continuum: de um processo com nenhum ou baixo grau de deliberação a um processo com alto grau de deliberação informada. A partir deste esquema, poder-se-ia construir modelos para abordar o tema da delibera- 
ção parlamentar de forma comparativa em diferentes casas legislativas.

Até então, as variáveis aqui enumeradas parecem sinalizar para um processo deliberativo com alto teor técnico. Considerando, porém, que a deliberação não envolve apenas uma discussão técnica em torno de políticas, mas é um processo eminentemente político, cabe assinalar outros aspectos importantes para assegurar um processo deliberativo informado. Entre estes, destaca-se a possibilidade de que os cidadãos e grupos potencial ou diretamente afetados por uma matéria possam participar do processo decisório. Além disso, deve-se considerar que o grau e a qualidade da deliberação possam variar dentro de uma mesma casa legislativa em função de outros aspectos: (a) os próprios temas, objeto de legislação, que, por variarem em grau de incerteza e interesse para os legisladores, podem influenciar a motivação para investir tempo e recursos na obtenção e na troca de informações (Becker, 1986; Elster, 1994); (b) o nível de autonomia dos legisladores para formar e transformar suas preferências que varia em função do poder das lideranças partidárias sobre suas bancadas; e (c) a possibilidade de incorporar, em formatos institucionais adequados, os atores afetados pelas decisóes, tais como os cidadãos e os grupos de interesse, no processo que as origina. ${ }^{16}$

Se a deliberação é o objeto de investigação do estudioso, isso implica em pensar métodos e técnicas específicas de análise e em fontes alternativas de investigação. Não se podendo inferir que, na presença das variáveis elencadas, a deliberação estará presente e será informada, os estudiosos da deliberação parlamentar devem ir além dos métodos tradicionalmente empregados nos estudos legislativos. Nesse caso, torna-se crucial incorporar métodos e técnicas qualitativas de investigação como análise de discurso, observação participante e entrevistas em profundidade com os parlamentares, que mobilizem como fontes o próprio conteúdo do debate, de modo que seja possível apreender o elemento da fala e o intercâmbio de argumentos. Os vários softwares desenvolvidos especificamente para a análise qualitativa oferecem ao analista uma ferramenta importante que lhe permite trabalhar com um volume maior de dados e buscar um equilíbrio entre as pretensóes de generalização e de aprofundamento na explicação.

A análise de discurso, técnica mais empregada em investigaçôes semelhantes, exige um esforço de classificação ex ante que atenue ao máximo possíveis vieses causados pelo subjetivismo de quem analisa. Um esquema classificatório focado no processo deliberativo poderia iluminar como os parlamentares deliberam sobre políticas ao contemplar os tipos, as direções, os conteúdos e as informações que podem estar presentes no debate. Tal esquema, ao ser aplicado à análise do discurso, pode iluminar como os legisladores deliberam sobre policies e auxiliar na verificação da existência ou não de nexos entre a organização informacional da casa legislativa e o processo deliberativo. Além disso, pode evidenciar em que medida as decisōes refletem, em seu conteúdo, o debate que precedeu sua aprovação.

Como se pode observar não se trata de uma empreitada simples. Trata-se de um campo muito pouco explorado, com enormes desafios teóricos, analíticos e metodológicos. Os inúmeros estudos empíricos produzidos na área da teoria deliberativa e participativa certamente oferecem referências importantes para a construção de modelos analíticos, sobretudo aqueles focados em arenas participativas com alto nível de institucionalização, como os orçamentos participativos e os conselhos setoriais de políticas públicas.

\section{Considerações finais}

O presente artigo abordou o tema da deliberação parlamentar chamando a atenção para a ausência de enfoques, no campo dos estudos legislativos, que tomem a deliberação como uma dimensão relevante da política parlamentar ao lado dos processos de negociação e de agregação de preferências. Buscou-se mostrar que a deliberação quase sempre esteve associada, em maior ou menor grau, ao governo representativo e que pode cumprir um importante papel no aperfeiçoamento da representação política.

O principal argumento desenvolvido foi o de que as teorias informacionais de organização legislativa apresentam interessantes pontos de encontro com o tema da deliberação e que, por essa razão, 
devem ser consideradas um ponto de partida para abordagens que visem explorar o elemento da argumentação, do debate e da discussão no processo legislativo. Também foram apresentadas algumas sugestôes para a construção de um modelo analítico capaz de apreender a dimensão da deliberação, bem como de métodos e técnicas que se mostram profícuos a essa tarefa.

Trata-se de um campo de estudos ainda pouco explorado e, por isso, repleto de incertezas e desafios teóricos e metodológicos. A saída, acredita-se, está em explorar, comparativamente, por meio de modelos analíticos bem elaborados, diferentes possibilidades para apreender o elemento deliberativo e, mais importante, distingui-lo dos processos de barganha e negociação

A suposição de haver um nexo entre a organização informacional do Legislativo e a dimensão deliberativa não deve desconsiderar as características da organização legislativa que restringem o debate e impedem que as matérias sejam exaustivamente estudadas e discutidas antes de serem decididas. $\mathrm{Da}$ mesma forma é preciso levar em conta as regras que tornam centrais os partidos ou outras instâncias decisórias no interior do parlamento e geram incentivos para o uso estratégico da informação e para o predomínio de outras formas de interação, sobretudo a negociação e os acordos entre lideranças partidárias. Essa questão foi apenas marginalmente abordada nesse artigo, necessitando, portanto, de maior atenção e reflexão.

Ao sustentar que a deliberação é um elemento relevante da política parlamentar não se propõe que os parlamentos sejam pensados como "arenas de deliberação ideal”, nem que a deliberação obedeça aos requisitos sociais, culturais ou políticos propalados pelos teóricos deliberativos. Relevante é investigar o quanto de deliberação se pode esperar nos parlamentos contemporâneos e as condições que favorecem uma deliberação informada, considerando a presença inescapável do conflito distributivo, do embate de interesses, do cálculo e da estratégia. Afirma-se, ao contrário dos teóricos deliberativos, a possibilidade real de, em meio a essa ampla gama de interaçôes, a deliberação se distinguir como forma de decisão capaz de aperfeiçoar a atividade representativa e a qualidade das decisões.

\section{Notas}

1 Neste artigo, deliberação, discussão, debate e argumentação são usados como termos intercambiáveis.

2 A questão de se a deliberação tem papel relevante na explicação dos resultados políticos é de grande relevância. Devido à escassez de estudos sobre o tema, acredita-se ser necessário investigar, primeiro, como a deliberação toma parte do processo legislativo e as condiçôes que a favorecem, para, depois, examinar seus impactos.

3 A noção de razoabilidade aqui empregada tem sentido semelhante ao de Cohen (1997) e Rawls (2002), para quem o pluralismo exige que pontos de vista sejam sustentados de modo que possam ser compreendidos e aceitos pelos outros, mesmos que estes não concordem quanto à dimensão substantiva do argumento.

4 Entres estes se destacam James Madison, Emmanuel Joseph Siéyès, Edmund Burke e John Stuart Mill.

5 Essa visão devia-se, em grande parte, ao medo de que a democracia viesse a acarretar a tirania de uma maioria sobre a minoria. Reservando a "homens notáveis" a tarefa de representar, esperava-se garantir às minorias, enfraquecidas na esteira das revoluções burguesas, um espaço de influência no novo regime.

6 Se os atributos pessoais dos legisladores contam, em alguma medida, isso decorre, em grande parte, de atributos desenvolvidos em função de sua própria trajetória como agentes públicos.

7 Nessa vertente, a deliberação é vista não apenas como método de tomada de decisão, ao lado de outros, mas como o principal procedimento de justificação política nas sociedades plurais.

8 Com "teorias positivas" designa-se as perspectivas teóricas que se desenvolveram no contexto dos estudos sobre o Congresso norte-americano e que buscaram se afastar das explicaçôes funcionalistas, adotando certos pressupostos de racionalidade e técnicas de análise com alto nível de formalização (Shepsle e Weingast, 1994).

9 Essa visão passou a predominar a partir dos estudos de Arrow (1963) e McKelvey (1976), que chamaram a atenção para o caráter cíclico da regra majoritária e para a importância das instituiçôes no sentido de estabilizar o processo de barganha coletiva.

10 Uma questão implícita a esse debate e explorada por Przeworski (1998) diz respeito a se os indivíduos transformam suas preferências em relação aos fins ou apenas aos meios mais adequados para alcançá-los. Os 
adeptos da Escolha Racional tendem a se inclinar para a primeira posição.

11 É importante assinalar que, embora esteja sendo tratada como uma única vertente teórica e analítica, a vertente deliberativa da democracia se caracteriza por um rico e produtivo debate interno, e seus autores encontram-se cientes da maioria das críticas aqui apresentadas.

12 Isso não quer dizer que a deliberação sempre funcionará como uma ferramenta que aperfeiçoa a representação. Reconhece-se que, em presença de grandes desigualdades entre os participantes, a deliberação possa produzir distorções e patologias. A esse respeito, ver Przeworski (1998).

13 Em geral, os distributivistas entendem a origem do sistema de comissões de modo diferente: sustentam que este serve ao propósito de permitir o processo de barganha em bases estáveis. Desse modo, a organização do Legislativo se compatibilizaria com as necessidades eleitorais de seus membros (Shepsle e Weingast, 1994).

14 Embora aqui o foco recaia sobre a dimensão substantiva do debate, em função do próprio conceito de deliberação adotado, reconhece-se que a discussão em torno dos procedimentos de tomada de decisão geralmente possui impactos sobre o debate substantivo.

15 No Congresso norte-americano, o veto ex-post é o mecanismo que possibilita às comissões manterem-se como veto group ao permitir que mudanças realizadas em uma proposta em estágios anteriores sejam anuladas no estágio final, quando a proposta é apreciada pela Comissão de Conferência (Shepsle e Weingast, 1987).

$16 \mathrm{O}$ modelo não considera as comunicações informais entre indivíduos, grupos de interesses e parlamentares que ocorrem fora dos canais institucionais e, por isso, são de difícil apreensão. Mas, reconhece se tratar de uma importante fonte de informação que, certamente, influencia a formação das preferências dos parlamentares.

\section{BIBLIOGRAFIA}

ANASTASIA, Fátima \& INÁCIO, Magna. (2006), "Democracia, Poder Legislativo, interesses e capacidades", in Câmaras municipais e prefeituras: transparência, controle e participação popular, Brasília, Câmara dos Deputados (mimeo.).
ARAÚJO, Cícero. (2004), "Razão pública, bem comum e decisão democrática", in $\mathrm{V}$. Schattan e M. Nobre, Participação e deliberação: teoria democrática e experiências institucionais no Brasil contemporâneo, São Paulo, Editora 34.

ARROW, Kenneth J. (1963), Social choice and individual values. 2 ed. New Haven, Yale university Press.

AUSTEN-SMITH, David. (1990), "Information transmission in debate". American Journal of Political Sciense, 34, 1: 124-52.

AVRITZER, Leonardo. (1996), A moralidade da democracia: ensaios em teoria habermasiana e teoria democrática. Belo Horizonte/São Paulo, Editora da UFMG/Perspectiva. . (2000), "Teoria democrática e deliberação pública'. Lua Nova, 50: 25-46.

BACHTIGER, A.; SPORNDLI, M.; STEENBERGEN, M. R. \& STEINER, J. (2005), "The deliberative dimensions of legislatures". Acta Política, 40: 225-38.

BECKER, Gary. (1986), "The economic approach to human behavior", in Jon Elster, Rational choice, Nova York, New York University Press.

BESSETTE, Joseph. (1994), The mild voice of reason: deliberative democracy and American national government. Chicago, The University of Chicago Press.

BOHMAN, James. (1997), "Deliberative democracy and effective social freedom: capabilities, resources, and opportunities", in James Bohman e William Rehg, Deliberative democracy: essays on reason and politics, Cambridge, MIT Press.

OHEN, Joshua. (1997), "Deliberation and democratic legitimacy", in James Bohman e William Rehg, Deliberative democracy: essays on reason and politics, Cambridge, MIT Press.

CONNOR, George \& OPPENHEIMER, B. (1993), "Deliberation: an untimed value in a timed game", in Lawrence Dodd e B. Oppenheimer, Congress reconsidered, Washington, D.C, CQ Press.

COX Gary W. \& MCCUBBINS, Matthew D. (1993), Legislative Leviathan: party government in the house. Berkley/Los Angeles, University of California Press. 
DOWNS, Anthony. (1999), Uma teoria econômica da democracia. Trad. de Sandra Guardini Teixeira Vasconcelos. São Paulo, Edusp.

ELSTER, Jon. (1994), Peças e engrenagens das ciências sociais. Trad. De Antônio Trânsito. Rio de Janeiro, Relume-Dumará.

(1997), "The marketing and the forum: three varieties of political theory", in James Bohman e William Rehg, Deliberative democracy: essays on reason and politics, Cambridge, MIT Press.

(1998), "Introduction" e "Deliberation and constitution making", in (ed.), Deliberative democracy, Cambridge, Cambridge University Press.

FISHKIN, James S. (1995), Voice of the people: public opinion and democracy. New Haven/Londres, Yale University Press.

GAMBETTA, Diego. (1998), "Claro!: An essay on discursive machismo", in J. Elster (ed.), Deliberative democracy, Cambridge, Cambridge University Press.

GARDNER, Joseph. (2005), "Deliberation and representation in Congress: allies or adversaries?". Paper presented at the annual meeting of the Western Political Science Association, Marriott Hotel, Oakland, California Online. Disponível em <http:/www.allacademic.com/ meta/p87325_index.html>.

GILLIGAN, Thomas W. \& KREHBIEL, Keith. (1987), "Collective decision-making and standing committees: an informational rationale for restrictive amendment procedures". Journal of Law, Economics and Organization, 3 (2): 287-335.

GUTMANN, Amy \& THOMPSON, Dennis F. (1996), Democracy and disagreement. Cambridge, Mass., Belknap Press of Harvard University Press.

HABERMAS, Jürgen. (1997), Direito e democracia: entre facticidade e validade. Trad. De Flavio Beno Siebeneichler. Rio de Janeiro, Tempo Brasileiro, vol. 2.

HAMILTON, Alexander; MADISON, James \& JAY, John. (1984), O federalista. Trad. De de Heitor Almeida Herrera. Brasília, Editora da Universidade de Brasília.
JOHNSON, James. (1998), "Arguing for deliberation: some skeptical consideration", in J. Elster (ed.), Deliberative democracy, Cambridge, Cambridge University Press.

JONES, Bryan D. (1994), Reconceiving decisionmaking in democratic politics: attention, choice e public policy. Chicago, The University of Chicago Press.

KREHBIEL, Keith. (1991), Information and legislative organization. Ann Arbor, University of Michigan Press.

LANDY, Marc K.; ROBERTS, Marc J. \& THOMAS, Stephen R. (1990), The environmental protection agency: asking the wrong questions. Nova York, Oxford University Press.

LASCHER, Edward. (2006), "Assessing legislative deliberation: a preface to empirical analysis". Legislative Studies Quarterly, 21: 501-519.

LIMONGI, Fernando. (1994), "O novo institucionalismo e os estudos legislativos: a literatura norte-americana recente". BIB - Boletim Informativo Bibliográfico, 37: 3-38.

MANIN, Bernard. (1995), "As metamorfoses do governo representativo". Revista Brasileira de Ciências Sociais, 10 (29): 5-34.

McLAVERTY, Peter \& HALPIN, Darren. (2008), "Deliberative drift: the emergence of deliberation in the policy process. International Political Science Review, 29 (2): 197-214.

MARCH, James G. (1986), "Bounded rationality, ambiguity, and the engineering of choice", in J. Elster (ed.), Deliberative democracy, Cambridge, Cambridge University Press.

MAYHEW, David. (1974), Congress: the electoral connection. New Haven, Yale University Press. . (2006), "Actions in the public sphere", in Paul J. Quirk e Sarah A. Binder (eds.), Institutions of American democracy: the legislative branch, Oxford, Oxford University Press.

McCUBBINS, Mathew D. \& RODRIGUEZ, Daniel B. (2006), "When does deliberating improve decisionmaking?” Disponível em <http://mccubbins.ucsd.edu/WhenDoesDeliberating.pdf>.

McKELVEY, Richard D. (1976), "Intransitivities in multidimensional voting models and some implications for agenda control". Journal of Economic Theory, 19: 472-482. 
MORROW, James D. (1994), Game theory for political scientists. New Jersey, Princeton University Press.

MUCCIARONI, Gary \& QUIRK, Paul J. (2006), Deliberative Choices: debating public policy in Congress. Chicago, The University of Chicago Press.

PITKIN, Hanna. (1967), The concept of representation. Berkley, University of California Press.

PRZEWORSKI, Adam. (1995), Estado e economia no capitalismo. Trad. de Argelina Cheibub Figueiredo e Pedro Paulo Zahluth Bastos. Rio de Janeiro, Relume-Dumará. . (1998), "Deliberation and ideological domination", in J. Elster (ed.), Deliberative democracy, Cambridge, Cambridge University Press.

POLSBY, Nelson. (1968), "The institutionalization of the U.S. House of Representatives". American Political Science Review, 62: 144-168.

RAWLS, John. (2002), Uma teoria da justiça. Trad. de Almiro Pisetta e Lenita M.R. Esteves. 2 ed. São Paulo, Martins Fontes.

REIS, Fábio W. (2000), Mercado e utopia: teoria politica e sociedade brasileira. São Paulo, Edusp.

RICCI, P. \& LEMOS, L. B. (2004), "Produção legislativa e preferências eleitorais na Comissão de Agricultura e Política Rural da Câmara dos Deputados". Revista Brasileira de Ciências Sociais, 19 (55): 107-129.

RIKER, William H. (1986), The art of political manipulation. New Haven/Londres, Yale University Press.

SARTORI, Giovanni. (1994), A teoria da democracia revisitada: o debate contemporâneo. Trad. de Dinah de Abreu Azevedo. São Paulo, Ática, vol. 1.

SCHUMPETER, Joseph A. (1961), Capitalismo, socialismo e democracia. Trad. de Ruy Jungmann. Rio de Janeiro, Jorge Zahar.

SEBATIER, Paul \& WHITEMAN, David. (1985), "Legislative decision making and substantive policy information: models of information flow". Legislative Studies Quarterly,10 (3): 395421.

SHEPSLE, Kenneth \& WEINGAST, Barry. (1994), "Positive theories of congressional ins- titutions”. Legislative Studies Quarterly, 19 (2): 149-179.

(1987), "Institutional foundations of committee power". American Political Science Review, 81: 85-104.

STENBERGEN, M. R.; BACHTIGER, A.; SPORNDLI, M. \& STEINER, J. (2003), "Measuring political deliberation: a discourse quality index". Comparative European Politics, 1: $21-48$

TSEBELIS, George. (1998), Jogos ocultos: escolha racional no campo da política comparada. São Paulo, Edusp.

WEBER, Max. (1982), "A política como vocação", in $\longrightarrow$ Ensaios de sociologia. Trad. de

Waltensir Dutra. 5 ed. Rio de Janeiro, Zahar Editores.

WEINGAST, B. R. \& MARSHALL, W. J. (1988), "The industrial organization of Congress: or, why legislatures, like firms, are not organized as markets". Journal of Political Economy, 96 (1): 133-163. 


\section{REPRESENTAÇÃO, DELIBERAÇÃO E ESTUDOS LEGISLATIVOS}

Marta Mendes da Rocha

Palavras-chave: Representação; Deliberação; Informação; Estudos legislativos; Teoria informacional.

O presente artigo aborda a relação entre representação e deliberação e problematiza a forma como estes temas vem sendo tratados no campo dos estudos legislativos. Apesar do tema da deliberação vir recebendo grande atenção na teoria democrática contemporânea, ele tem sido negligenciado pelos estudiosos do Poder Legislativo. Neste artigo discutem-se as relaçōes entre deliberação e representação na teoria e na prática da democracia representativa. Busca-se desenvolver o argumento de que o modelo informacional de organização legislativa apresenta importantes nexos com o tema da deliberação podendo se converter em uma alternativa viável para compreender como o debate toma parte do processo decisório no âmbito do parlamento e quais são as condiçōes que favorecem uma deliberação informada.

\section{REPRESENTATION, DELIBERATION, AND LEGISLATIVE STUDIES}

Marta Mendes da Rocha

Keywords: Representation; Deliberation; Information; Legislative studies; Informational theory

The present article aims at approaching the relationship between representation and deliberation and discusses the way these themes have been dealt with in the field of legislative studies. Despite the attention placed on the theme of deliberation by the contemporary democratic theory, it has been neglected by scholars of Legislature. This article discusses the relationship between deliberation and representation in the theory and practice of representative democracy. We seek to develop the argument that the informational model of legislative organization has important linkages with the theme of deliberation, being able to turn into a feasible alternative to understand how the debate takes part in the decision-making process within the parliament and what conditions will foster an informed deliberation.

\section{REPRÉSENTATION, DÉLIBÉRATION ET ÉTUDES LÉGISLATIVES}

\section{Marta Mendes da Rocha}

Mots-clés: Représentation; Délibération; Information; Études législatives; Théorie informationnelle.

Cet article aborde la relation entre représentation et délibération et discute la façon dont ces questions sont traitées dans le domaine des études législatives. Malgré le fait que le thème de la délibération soit traité avec priorité par la théorie démocratique contemporaine, il a été négligé par les chercheurs du Pouvoir Législatif. Larticle discute les rapports entre délibération et représentation, en théorie et dans la pratique de la démocratie représentative. Il cherche à développer l'argument selon lequel le modèle informationnel d'organisation législative présente des liens importants avec le thème de la délibération et peut devenir une alternative viable pour comprendre de quelle façon le débat participe du processus décisionnel au sein du Parlement, et quelles sont les conditions qui favorisent une délibération informée. 